\title{
Benzaldehyde Dimethane Sulfonate
}

National Cancer Institute

\section{Source}

National Cancer Institute. Benzaldehyde Dimethane Sulfonate. NCI Thesaurus. Code C107164.

A dimethane sulfonate derivative and alkylating agent with a structure similar to other alkylating agents such as chlorambucil, busulfan and melphalan, with potential antineoplastic activity. Although the exact mechanism of action has yet to be fully elucidated, benzaldehyde dimethane sulfonate alkylates DNA, which results in DNA double strand breaks, inhibition of DNA replication, cell cycle arrest and cell death. In addition, this agent is metabolized by the enzyme aldehyde dehydrogenase (ALDH) into the active carboxylic acid metabolite benzoic acid dimethane sulfonate (BA), which further contributes to its alkylating activity. Unlike other alkylating agents, benzaldehyde dimethane sulfonate has demonstrated antitumor activity in renal cell carcinoma. 